\title{
Infecções por Staphylococcus aureus: mudança do perfil epidemiológico no Hospital Universitário Pedro Ernesto
}

\author{
Staphiloccocus aureus infections: change in epidemiology at \\ Pedro Ernesto University Hospital
}

\author{
Júlio C. D. Correal ${ }^{*}$ \\ Elizabeth de Andrade Marques \\ Werneck Loureiro Guilherme \\ Robson de Souza Leão \\ Paulo Vieira Damasco
}

\section{Resumo}

As infecções relacionadas à assistência em saúde (IRAS) representam um crescente problema pelas consequências na mortalidade dos pacientes e pelos altos custos na assistência a estes enfermos. Atualmente, o Staphylococcus aureus é considerado um dos micro-organismos mais importantes mundialmente no contexto das IRAS. O Staphylococcus aureus resistente à meticilina (MRSA) foi inicialmente descrito como um patógeno associado às infecções relacionadas à assistência em saúde. Porém, um clone de MRSA, o CA-MRSA emergiu na comunidade causando infecções graves - tais como infecções de pele e anexos, fasceíte necrotizante, abscessos intra-abdominais, infecção da corrente sanguínea ou bacteremia, sepse, artrite séptica, osteomielite, endocardite, meningite, infecções relacionadas a uso de cateteres intra- vasculares ou cateteres vesicais e pneumonia (comunitária e hospitalar, associada ou não à ventilação mecânica) - e está atualmente predominando nos hospitais brasileiros. O objetivo deste artigo é descrever aspectos relacionados com a epidemiologia das infecções por cepas CA-MRSA no Hospital Universitário Pedro Ernesto, avaliando especificamente fatores de risco relacionados com as infecções por CA-MRSA. Foi realizado um estudo retrospectivo das infecções/colonizações de fevereiro de 2005 até julho de 2011. Nas análises das tendências temporais da apresentação dos subtipos de MRSA foi observada uma diminuição no número de cepas de MRSA multirresistente (HA-MRSA) $(\mathrm{p}<0,05)$ e uma tendência ao aumento de cepas não multirresistentes (CA-MRSA); mas sem alcançar a significância estatística $(\mathrm{p}=0,06)$. Não houve associação entre o fenótipo específico de MRSA e a mortalidade devida à infecção por cepas 
MRSA. Uma idade acima de 70 anos (OR: 2,46, IC95\%: 0,99-6,11), a presença de pneumonia adquirida no hospital (OR: 4,94, IC95\%: 1,65 - 14,8), a doença pulmonar obstrutiva crônica (OR: 6,09, IC95\% 1,16-31,98) e a leucemia (OR: 8,2, IC95\%: 1,25 - 54,7) foram fatores de risco associados à mortalidade nas infecções por cepas de $S$. aureus.

Descritores: Staphylococcus aureus resistente à Meticilina; Infecção hospitalar; Epidemiologia; Fatores de risco; Estudos retrospectivos.

\section{Abstract}

The healthcare-associated infections (HAIs) represent an increasing problem due to the consequences on patient mortality and the high associated-costs of the medical assistance. Currently, Staphylococcus aureus is considered one of the most important microorganisms in the context of worldwide HAIs. The methicillin resistant Staphylococcus aureus (MRSA) was first described as a pathogen associated with infections related to health care, but a clone of MRSA, the community-associated (CA) CAMRSA emerged in the community leading cause serious infections such as skin and soft tissues infections, necrotizing fasciitis, intra-abdominal abscesses, bloodstream infection, sepsis, septic arthritis, osteomyelitis, endocarditis, meningitis, infections related to intravascular catheters or bladder catheters and pneumonia (community-acquired and healthcare-associated, with or without mechanical ventilation) and is currently prevalent in many Brazilian hospitals. The aim of this article was to describe issues of the epidemiology of infections due to CA-MRSA in the Pedro Ernesto University Hospital of Rio de Janeiro City, focusing in risk factors related with infections due to this pathogen. For this purpose was done a retrospective study of the infections/ colonization from February 2005 to July 2011. In the temporal analysis on presentation of MRSA phenotypes were observed a decreasing trend of presence of multidrug-resistant (MDR)
MRSA clones (HA-MRSA like) $(\mathrm{p}<0.05)$ and a slightly increase in the non-MDR MRSA (CAMRSA like), but without reaching statistic significance $(\mathrm{p}=0.06)$. There was no association between a specific $S$. aureus phenotype and the fatal outcomes in infectious episodes. Aging (above 70 years-old) (OR: 2.46, IC95\%: 0.99 6.11), healthcare-associated pneumonia (OR: 4.94, IC95\%: 1.65 -14.8), chronic obstructive pulmonary disease (OR: 6.09, IC95\% 1.16 31.98) and leukemia (OR: 8.2, IC95\%: 1.25 54.7) were risk factors associated with mortality in this patient settings.

Keywords: Methicillin-resistant Staphylococcus aureus; Cross infection; Epidemiology; Risk factors; Retrospective studies.

\section{Introdução}

As infecções relacionadas à assistência em saúde (IRAS) representam um crescente problema pelas consequências na mortalidade dos pacientes e pelos altos custos na assistência a estes enfermos. Atualmente, o Staphylococcus aureus é considerado um dos micro-organismos mais importantes mundialmente no contexto das IRAS. ${ }^{1}$

S. aureus é uma bactéria anaeróbia facultativa, descrita pela primeira vez por Alexander Ogston, em 1880. É um coco gram-positivo imóvel, não esporulado que produz coagulase e frequentemente é não encapsulado ou tem uma cápsula limitada. Também mostra resultado positivo no teste da proteína A ligada a fibrinogênio (fator clumping). ${ }^{2} \mathrm{O}$ primeiro passo na patogênese do $S$. aureus é a colonização; os indivíduos colonizados assintomáticos são o principal reservatório para a disseminação inter-humana e, mais recentemente, zoonótica. Para iniciar uma infecção por S. aureus, este primeiro deve se aderir aos tecidos ou aos dispositivos protéticos e, para conseguir isso, usa uma grande variedade de proteínas de superfície conhecidas como moléculas adesivas da matriz reconhecedoras de componentes da superfície (microbial surface components recognizing adhe- 
sive matrix molecules - MSCRAMMS). ${ }^{3}$ Uma vez fixado à superfície, o $S$. aureus aproveita seus recursos para escapar do sistema imune do hospedeiro e obter tempo suficiente para desenvolver a infecção. Um desses mecanismos é a formação de biofilmes, que são coleções extracelulares de polímeros produzidas pela bactéria e que garantem as condições de proteção contra as defesas imunológicas e a ação dos antimicrobianos. Uma vez as circunstâncias sendo favoráveis, ocorre a invasão tecidual, para a qual o $S$. aureus desenvolve vários mecanismos dependentes de proteínas de superfície para sobreviver ao sistema imune do hospedeiro. A cápsula antifagocítica é o mecanismo primário contra a atividade fagocítica de neutrófilos, monócitos e macrófagos. ${ }^{4}$ Além da cápsula, estudos moleculares têm demonstrado que o $S$. aureus usa proteínas ligantes de fibronectina (um tipo de MSCRAMM) para evadir-se da fagocitose. Especificamente, para encontrar proteção, esta bactéria cria pontes de fibronectina com a célula endotelial do hospedeiro usando as integrinas $\beta-1$ e assim conseguindo sua internalização e proteção das células do sistema imune extracelular. ${ }^{5}$ Para evitar a imunidade mediada por anticorpos, o $S$. aureus utiliza uma proteína de superfície chamada proteína A (codificada pelo gene $s p a$ ). Uma vez ligada à região $\mathrm{Fc}$ das imunoglobulinas do hospedeiro, a proteína $\mathrm{A}$ inibe a opsonização e a fagocitose. O S. aureus também utiliza secreção de proteínas para sua defesa do sistema de fagocitose do sistema imune. Aproximadamente $50 \%$ dos isolados de $S$. aureus secretam uma substância chamada proteína inibitória de quimiotaxia (chemotaxis inhibitory protein of S. aureus - CHIPS), a qual limita o recrutamento de neutrófilos. Estas bactérias também produzem leucocidinas, que são fatores que podem atacar e destruir as membranas dos leucócitos mediante a formação de poros. Um tipo particular de leucocidina é a toxina de Panton-Valentine (PVL), cujos genes estão codificados em um bacteriófago integrado ao genoma bacteriano. ${ }^{6}$

Outros fatores secretados incluem: $\beta$-lactamases, proteases, lipases, nucleases, liases de ácido hialurônico, fosfolipase $\mathrm{C}$ e metaloproteinases, que também são importantes na disseminação da infecção e na destruição tissular. Além dos mecanismos descritos, numerosas cepas produzem toxinas com capacidade de criar distúrbios fisiológicos específicos. As toxinas classificadas como superantígenos produzem uma tormenta de citoquinas, assim como aumento na proliferação clonal de células T. Um destes superantígenos é a toxina da síndrome de choque tóxico estafilocóccico (Toxic Shock Syndrome Toxin-1 - TSST-1), configurando um quadro clínico agressivo e devastador denominado síndrome de choque tóxico. A toxina esfoliativa induz eritema assim como esfoliação da pele, fenômeno observado na síndrome de pele escaldada. Uma vez atravessando as barreiras naturais o $S$. aureus consegue evadir-se do sistema imune e pode causar infecções graves, tais como infecções de pele e anexos, fasceíte necrotizante, abscessos intra-abdominais, infecção da corrente sanguínea ou bacteremia, sepse, artrite séptica, osteomielite, endocardite, meningite, infecções relacionadas a uso de cateteres intravasculares ou cateteres vesicais e pneumonia (comunitária e hospitalar, associada ou não à ventilação mecânica), e mais recentemente a fístula carótido-cavernosa após bacteremia por $S$. aureus. ${ }^{7}$

\section{Mecanismos de resistência do}

\section{S. aureus à meticilina}

A parede bacteriana é importante para manter a forma da célula e é o principal mecanismo para evitar a lise osmótica. Assim, agentes farmacológicos que destroem os componentes bacterianos críticos podem ser bactericidas. A penicilina, um antibiótico $\beta$-lactâmico, une-se em forma covalente e inibe a ação das proteínas ligantes de penicilina (Penicillin-Binding Proteins - PBPs), as quais são as responsáveis pela construção, manutenção e regulação da porção de peptidoglicanos da parede celular.

O S. aureus normalmente tem quatro PBPs 


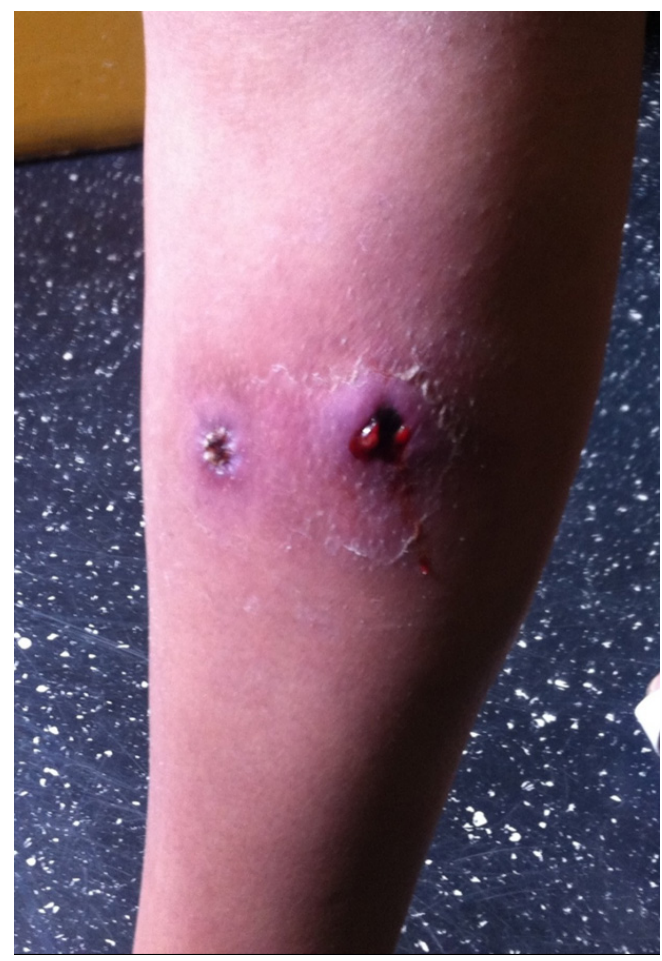

Figura 1. Paciente encaminhado ao ambulatório de doenças infecciosas e parasitárias do Hospital Universitário Pedro Ernesto (HUPE/UERJ) na policlínica Piquet Carneiro com abscesso cutâneo por Staphylococcus aureus de perfil comunitário (CA-MRSA)

Fonte: Imagem cedida pelo Dr. Damasco

(PBP1-4); as PBP1, PBP2 e PBP3 são essenciais e exibem grande afinidade por antibióticos $\beta$-lactâmicos, entretanto as PBP4, que favorecem o enlace externo cruzado do peptidoglicano bacteriano, têm baixa afinidade por estes antimicrobianos. ${ }^{8}$

Em 1959 foi introduzida no mercado a meticilina. Desafortunadamente, os primeiros casos de $S$. aureus resistente à meticilina (Meticillin-Resistant Staphylococcus aureus MRSA) apareceram um ano após e em menos de uma década foi observado o primeiro surto no hospital de Boston em quase 20 pacientes, com evidência de disseminação hospitalar. $\mathrm{O}$ principal mecanismo de resistência à meticilina em $S$. aureus envolve a presença cromossômica do elemento mecA, um fragmento de DNA externo de 40-60 kilobases que codifica para as PBPS com baixa afinidade aos antibióticos $\beta$-lactâmicos.

Adicionalmente, o $S$. aureus produz quatro tipos de $\beta$-lactamases (A, B, C e D) que podem hidrolisar as penicilinas, penicilinas naturais e semissintéticas e cefalosporinas. ${ }^{9}$

\section{O cassete estafilocócico cromossomal mec (SCCmec)}

O gene mecA codifica uma proteína de 76 $\mathrm{kDa}$ chamada PBP2a. São descritos 12 tipos de PBPs (PBP1-PBP12) e em $S$. aureus são descritos os tipos PBP1-PBP4. A resistência a $\beta$-lactâmicos no MRSA é mediada pelo tipo PBP2a (ou PBP2') e no CA-MRSA adicionalmente pelo $\mathrm{PBP} 4$. Esse gene é carreado em um elemento genético identificado como elemento genético móvel estafilocócico (Staphylococcal cassette chromosome mec-SCCmec). Para facilitar sua mobilização o SCCmec contém genes de enzimas recombinases específicas denominadas recombinases cromossomais do SCCmec (cassette chromosome recombinases - ccr, que podem ser do tipo $c c r \mathrm{~A}, c c r B$ ou $c c r C)$. Atualmente são conhecidos 11 tipos de SCCmec (tipo I - XI) em MRSA, sendo que os SCCmec tipo IV ao XI estão associados com menor resistência aos antibióticos não $\beta$-lactâmicos que os SCCmec tipo I ao III..$^{10}$

\section{HA-MRSA e CA-MRSA}

O MRSA foi inicialmente descrito como um patógeno associado à infecção hospitalar; caracteristicamente com maior resistência aos antimicrobianos não $\beta$-lactâmicos, também chamado MRSA tradicional ou MRSA adquirido no ambiente hospitalar (hospital-acquired MRSA ou HA-MRSA). Ao final da década de 90 foi documentado na Austrália o surgimento de uma nova variedade de MRSA, o clone USA 300 que inicialmente foi descrito como MRSA adquirido na comunidade (CommunityAdquired Methicillin-Resistant Staphylococcus aureus e hoje denominado na literatura como Community-associated Methicillin-Resistant Staphylococcus aureus - CA-MRSA), de acordo com critérios epidemiológicos definidos pelo Centro para o Controle e Prevenção de Doenças 


\section{a scCmecll}

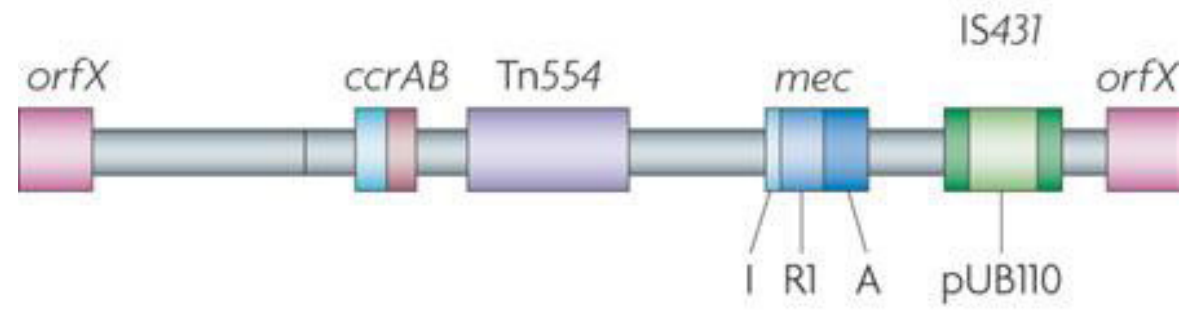

b SCCmecIV

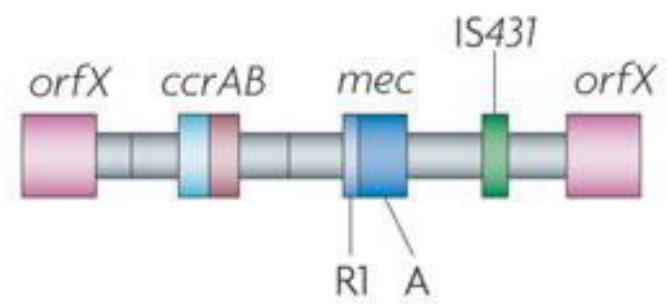

Figura 2. Classificação esquemática dos tipos de cassete estafilocócico cromossomal mec (SCCmec) por tipo de complexo ccr e gene mec

Fonte: Adaptado de Community-Associated Methicillin-Resistant Staphylococcus aureus: epidemiology and clinical consequences of an emerging epidemic, 2010. ${ }^{14}$

dos Estados Unidos (Center for Disease Control and Prevention - CDC). ${ }^{11}$ Devido a sua disseminação nos hospitais e serviços de saúde, a definição de CA-MRSA está atualmente em debate e outras denominações como, MRSA de perfil comunitário (community-like MRSA) ou MRSA não multirresistente (non-multiresistant MRSA) tem sido sugeridas e utilizadas na comunidade científica. CA-MRSA tem várias características que os tornam distinguíveis das amostras hospitalares (HA-MRSA). As cepas CA-MRSA são sensíveis a uma variedade importante de antibióticos não $\beta$-lactâmicos, enquanto os HA-MRSA são tipicamente resistentes a múltiplos antibióticos. As cepas CA-MRSA no setor comunitário possuem até em $90 \%$ dos isolados, a toxina PVL, que é codificada pelos genes lukS-PV e lukF-PV. ${ }^{12}$ A disseminação destas cepas e seu caráter epidêmico estão relacionados com as mudanças relacionadas à prestação dos serviços de saúde com ênfase em programas ambulatoriais para tratamento de pacientes crônicos (hemodiálise, diálise peritoneal, terapia antimicrobiana ambulatorial, programas de hospital dia e asilos de longa permanência entre outros), que favoreceram a disseminação dos clones na comunidade. As condições próprias do meio comunitário podem ter selecionado os clones de CA-MRSA. A heterogeneidade das cepas CA-MRSA e o pequeno tamanho dos SCCmec tipo IV ao XI, sugerem que esses alótipos têm maior facilidade para se transmitir (o SCCmec tipo IV tem um tamanho de apenas 20,9-24,3 kb) comparado com os grandes e pesados SCCmec tipo I ao III $(54-67 \mathrm{kd}){ }^{13}$ Estas características conferem ao CA-MRSA vantagens competitivas relacionadas com duplicação celular e capacidade de disseminação nos ambientes comunitários e nos serviços de saúde. ${ }^{14}$

\section{Características clínicas das infecções por CA-MRSA}

Classicamente as infecções relacionadas ao CA-MRSA foram observadas nos pacientes ambulatoriais e em unidades de emergência, causando surtos entre atletas, crianças, presos, populações indígenas na Austrália, militares, populações indígenas da América do Norte, e homossexuais masculinos. As síndromes infecciosas variavam desde infecções de pele e tecidos moles purulentas ou necrotizantes menores até infecções sistêmicas graves, incluindo fasceíte necrotizante e pneumonia. Posteriormente, em 2004, foi demonstrado que muitas infecções de corrente sanguínea (ICS) nosocomiais foram causadas pela cepa MRSA USA300 (um clone 
de CA-MRSA). ${ }^{15}$

\section{Morbidade e mortalidade da infecção pelo MRSA}

Diversos estudos incluindo algumas metanálises mostram maior mortalidade entre os pacientes com MRSA, quando comparados com pacientes com infecções por MSSA e muitos destes pacientes tiveram tempos de internação prolongados e maiores custos associados à terapêutica. Os indivíduos com patologias dermatológicas que alterem a função de barreira da pele como dermatite, psoríase e doenças eczematosas têm aumento da taxa de colonização e infecção pelo CA-MRSA, especialmente as populações pediátricas. Também o uso de terapias com medicamentos que afetam a imunidade (glucocorticosteroides; drogas citotóxicas tais como o metrotexato, azatioprina, ciclofosfamida, clorambucil; inibidores da calcineurina; imunossupressores como o tacrolimo, pimecrolimo e o sirulimo; os imunomoduladores biológicos ou anticorpos monoclonais), aumentam o risco de infecções graves por CA-MRSA nesse grupo de pacientes. ${ }^{16}$

No Brasil, Moreira e colaboradores avaliaram pacientes com infecção pelo MRSA em um hospital universitário e também encontraram maior número de casos de sepse e mortalidade entre pacientes com bacteremia por MRSA. ${ }^{17}$

\section{Tratamento das infecções por CA-MRSA}

As infecções cutâneas e de tecidos moles são as formas clínicas mais frequentes de infecção por CA-MRSA e envolvem duas terapêuticas: o uso de antimicrobianos adequados em dose, tipo e via de administração, e a drenagem das coleções purulentas precocemente. ${ }^{18}$ Os quadros infecciosos que envolvem presença de toxinas (por exemplo, na síndrome de choque tóxico) adicionalmente ao uso do antimicrobiano deve ser instituída uma terapia para o controle dos sintomas. Assim, na síndrome de choque tóxico a terapia agressiva de reposição de líquido e de controle da hipotensão é obrigatória. Alguns estudos têm demonstrado a utilidade de terapia com imunoglobulina específica. ${ }^{19}$ Nas formas clínicas potencialmente graves estão indicados: vancomicina ou teicoplanina, daptomicina, quinupristina/dalfopristina, dalbavancina, telanvancina, ornitavancina, tigeciclina e linezolida. No entanto, temos observado na revisão da literatura e no HUPE aumento crescente da CIM (concentração inibitória mínima) para vancomicina e principalmente para teicoplanina nas amostras de S. aureus (MRSA e MSSA). Associações destes antibióticos com $\beta$-lactâmicos (especialmente à oxacilina) é controversa no tratamento empírico das infecções por S. aureus. Por outro lado, a demora no início da oxacilina aumenta dramaticamente a mortalidade em pacientes com infecções por MSSA, quando só se utiliza vancomicina ou daptomicina como terapia antimicrobiana empírica inicial. ${ }^{20}$

Apesar do sinergismo observado in vitro, associações com antibióticos não $\beta$-lactâmicos, como a rifampicina e aminoglicosídeos, cada vez são menos frequentes devido aos efeitos adversos, especialmente pela nefrotoxicidade. Novos medicamentos anti-MRSA, como as cefalosporinas de $5^{\underline{a}}$ geração, prometem bons resultados no tratamento de infecções graves como a pneumonia ou a endocardite. O ceftobiprole e o ceftaroline que apresentam alta afinidade pela PBP2a são alternativas interessantes a vancomicina, daptomicina ou linezolida. Os resultados dos primeiros testes in vitro no Brasil usando ceftobiprole foram satisfatórios frente a amostras de MRSA. ${ }^{21}$

Existem aspectos limitantes na terapêutica antimicrobiana das infecções graves por CA-MRSA, entre eles: o aumento da resistência a antimicrobianos potencialmente utilizáveis como a clindamicina, tetraciclinas, rifampicina, ciprofloxacina e mupirocina; e as desvantagens no uso do sulfametoxazol/trimetoprima em presença de coleções ou grandes quantidades de inóculo. Lembramos a ineficiência para atingir concentrações terapêuticas nos tecidos observada no uso de vancomicina, daptomicina 
e a toxicidade associada ao uso prolongado da linezolida ou a nefrotoxicidade relacionada ao uso de vancomicina, teicoplanina, daptomicina ou rifampicina. ${ }^{22} \mathrm{O}$ esquema proposto para tratamento de infecções por CA-MRSA no HUPE aparece na tabela 1.

\section{Epidemiologia das infecções por MRSA}

São fatores de risco para a aquisição de HA-MRSA e HCA-MRSA, o contato prévio com serviços de saúde, tais como diálise, cirurgia, internação, residência em instituições de longa permanência ou cirurgia prévia no último ano; presença de cateteres; dispositivos médicos transcutâneos ou história de infecção recente por MRSA. ${ }^{23}$ Alguns estudos têm descrito surtos de CA-MRSA na comunidade ou no período de 72 horas após a internação hospitalar. Recentes estudos têm sugerido que as cepas CA-MRSA podem estar se disseminando nos ambientes hospitalares causando infecções que podem se classificar como hospitalares. ${ }^{15}$ A potencial substituição dos HA-MRSA pelos CA-MRSA, tem várias implicações importantes no controle de infecção. As atuais recomendações têm como objetivo diminuir a taxa de transmissão do MRSA dentro dos hospitais, porém a efetividade das intervenções para controlar as cepas CAMRSA são desconhecidas. Por exemplo, o controle na prescrição de ciprofloxacina tem sido proposto para diminuir as taxas de infecção por MRSA nos hospitais e na análise de Popovich e colaboradores, o uso prévio de ciprofloxacina três meses antes da infecção foi um fator de risco significativo para as infecções associadas a HA-MRSA e não para o CA-MRSA. ${ }^{24}$ Embora os mecanismos de colonização/infecção pelas cepas CA-MRSA sejam desconhecidos, sabe-se que podem colonizar sítios anatômicos diferentes do HA-MRSA. Assim, a efetividade no controle dos CA-MRSA usando culturas de swab nasal para a vigilância da colonização por MRSA

Tabela 1. Características clínicas e epidemiológicas de pacientes com infecções/colonizações por Staphylococcus aureus no HUPE/UERJ (2005-2011)

\begin{tabular}{|c|c|c|c|}
\hline \multirow[t]{2}{*}{ Características } & MSSA & Perfil-CA-MRSA & Perfil-HA-MRSA \\
\hline & $(n=814)$ № (\%) & ( $n=276)$ № (\%) & ( $n=216)$ № (\%) \\
\hline Mortalidade global" & $207(25,4)$ & $98(35,5)$ & $94(43,5)$ \\
\hline Gênero masculino* & $408(50,1)$ & $169(61,2)$ & $131(60,6)$ \\
\hline Idade média $\pm \mathrm{DP}(\text { anos) })^{*}$ & $47 \pm 23$ & $50 \pm 23$ & $54 \pm 21$ \\
\hline Tempo de permanência hospitalar (dias) & $52,2 \pm 5,2$ & $69,8 \pm 4,9$ & $58 \pm 3,3$ \\
\hline Internação anterior (3 meses) & $410(50,4)$ & $153(55,3)$ & $97(44,9)$ \\
\hline Tempo para cultura positiva por S. aureus & $24,4 \pm 3,72$ & $38,7 \pm 3,85$ & $29,1 \pm 2,15$ \\
\hline \multicolumn{4}{|l|}{ Setor de coleta } \\
\hline Clínica médica & $238(29,2)$ & $101(36,6)$ & $66(30,5)$ \\
\hline Clínica cirúrgica & $181(22,2)$ & $40(14,5)$ & $44(20,3)$ \\
\hline UTI adulto & $142(17,4)$ & $69(25)$ & $74(34,2)$ \\
\hline Pediatria & $77(9,45)$ & $18(6,5)$ & $10(4,6)$ \\
\hline Nefrologia & $158(19,4)$ & $38(13,8)$ & $18(8,3)$ \\
\hline UTI pediátrica & $18(2,2)$ & $10(3,6)$ & $4(1,8)$ \\
\hline \multicolumn{4}{|l|}{ Espécime clínico } \\
\hline Sangue & $318(39,1)$ & $122(44,2)$ & $70(32,4)$ \\
\hline Secreção/Biópsia pele/Tecidos moles & $153(18,8)$ & $38(13,8)$ & $18(8,3)$ \\
\hline Aspirado de secreçnao traqueal/LBA & $122(15)$ & $38(13,8)$ & $64(29,6)$ \\
\hline Secreções/Biópsia osso e articulações & $20(2,5)$ & $5(1,8)$ & $3(1,38)$ \\
\hline Urina/Secreção genital & $67(8,2)$ & $10(3,6)$ & $15(6,9)$ \\
\hline Coleções/Biópsia intra-abdominal & $26(3,1)$ & $6(2,1)$ & $8(3,7)$ \\
\hline Secreções de ferida operatória/Biópsia & $60(7,3)$ & $24(8,7)$ & $18(8,3)$ \\
\hline Liquor & $5(0,6)$ & $2(0,72)$ & $1(0,5)$ \\
\hline Cultura de ponta de cateter & $43(5,2)$ & $31(11,2)$ & $19(8,8)$ \\
\hline
\end{tabular}

MRSA = Staphylococus aureus resistente a meticilina; $\mathrm{HA}-\mathrm{MRSA}=$ adquirido no hospital; $\mathrm{CA}-\mathrm{MRSA}=\mathrm{MRSA}$ adquirido na comunidade; DP = desvio padrão; UTI = Unidade de tratamento intensivo; LBA= Lavado bronco-alveolar. "Valor $p<0,05$. 
com fins de isolamento e/ou da descolonização com mupirocina é desconhecida. ${ }^{25}$

\section{Situação atual do CA-MRSA no Brasil}

Os primeiros casos de infecções causadas por CA-MRSA no Brasil foram documentados no hospital das clínicas da Universidade de São Paulo, muitos deles com perfil não multirresistente (Non-MDR MRSA) e contendo o elemento SCCmec IV. ${ }^{26} \mathrm{~A}$ emergência no Brasil de cepas do tipo SCCmec IV, geneticamente relacionadas com o clone USA 800, foram reportadas em hospitais do Rio de Janeiro e de Porto Alegre, sem descrição dos fatores de risco associados à infecção ou colonização clássicos de 2005. O padrão epidemiológico do CA-MRSA no Brasil também está mudando. Atualmente os fatores de risco para infecções por CA-MRSA adquiridos no meio hospitalar são semelhantes aos fatores de risco clássicos descritos nas infecções por HA-MRSA.

\section{Disseminação do MRSA nos serviços de saúde}

A disseminação do MRSA nos serviços de saúde aumentou constantemente nas últimas décadas, sendo reportados surtos em unidades intensivas cirúrgicas, de neonatos, de queimados, de clínica médica e centros cirúrgicos. A transmissão cruzada entre pacientes e profissionais da saúde é uma das principais causas dos surtos. Estudo realizado no Hospital Universitário Pedro Ernesto (HUPE), publicado recentemente, ${ }^{27}$ no qual foram apresentadas as características clínicas e microbiológicas de 1.299 pacientes com 1.306 culturas positivas para $S$. aureus, mostrou antecedente de internação recente em 29,2\% dos casos, sendo IRAS em $64,3 \%$ dos casos. Os pacientes provinham de diferentes setores do hospital: clínica médica (31\%), clínica cirúrgica (20,3\%), UTI adultos $(21,8 \%)$, pediatria $(8 \%)$, nefrologia, incluindo hemodiálise e diálise peritoneal ambulatorial $(16,4 \%)$ e UTI pediátrica
(2,4\%). Os espécimes clínicos mais frequentes foram hemoculturas (39\%), secreção/biópsia de pele e tecidos moles (23,8\%), secreção traqueal/ lavado broncoalveolar $(17,1 \%)$ e culturas de ponta de cateter $(7,1 \%)$. A resistência global dos $S$. aureus aos antimicrobianos foi: oxacilina $(37,7 \%)$, penicilina $(90 \%)$, clindamicina $(34,1 \%)$, eritromicina $(39,3 \%)$, ciprofloxacina (30\%), sulfametoxazol-trimetoprima (10,5\%), cloranfenicol $(16,7 \%)$, tetraciclina $(14,4 \%)$ e gentamicina (14,6\%). A mortalidade geral neste grupo de pacientes foi de 30,5\%. Usando uma regra de predição fenotípica baseada em estudos prévios que utilizaram comparação dos genótipos e fenótipos de 606 amostras de MRSA no Brasil, no HUPE foram observadas 276 cepas $(21,1 \%)$ que corresponderam ao perfil-CA-MRSA, 216 (16,5\%) ao perfil-HAMRSA e $814(62,3 \%)$ a $S$. aureus sensível à meticilina (MSSA). As principais características clínicas e demográficas dos pacientes infectados/ colonizados pelos diferentes perfis de S. aureus são apresentados na tabela 2 .

Para a maioria das variáveis analisadas não houve diferença significativa entre os fenótipos de S. aureus. A mortalidade foi maior nos pacientes com perfil-HA-MRSA (43,5\%; OR: 1,98 IC95\%: 1,4-2,6) e perfil-CA-MRSA (35,5\%, OR: 1,35 IC95\%: 1-1,7) comparados com o perfil-MSSA (25,4\%; OR: 0,53; IC95\%: 0,41-0,68). A comparação da mortalidade entre HA-MRSA e CA-MRSA pelo teste de Bonferroni não foi significativa $(\mathrm{p}=0,25)$. A idade dos pacientes com perfil-HA-MRSA $(54,6 \pm 1,4)$ e perfil-CA-MRSA $(50,6 \pm 1,4)$ foi ligeiramente maior do que aqueles com perfil-MSSA $(47,2 \pm 0,8)(\mathrm{p}<0,05)$. Houve maior número de episódios de colonização/ infecção em pacientes masculinos com MRSA (61\% e $60 \%$ para HA-MRSA e CA-MRSA respectivamente) comparados com os MSSA $(50 \%)(\mathrm{p}<0,05) . \mathrm{Na}$ análise das tendências temporais de apresentação dos fenótipos de S. aureus usando dados ajustados mostraram uma diminuição constante do número de infecções/colonizações pelo perfil-HA-MRSA, 
Tabela 2. Tratamento de infecções por S. aureus no HUPE/UERJ (2012)
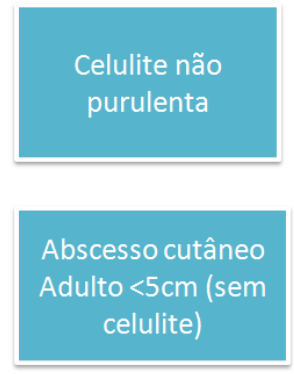

Abscessos

cutâneos $>5 \mathrm{~cm}$ ou associados a:
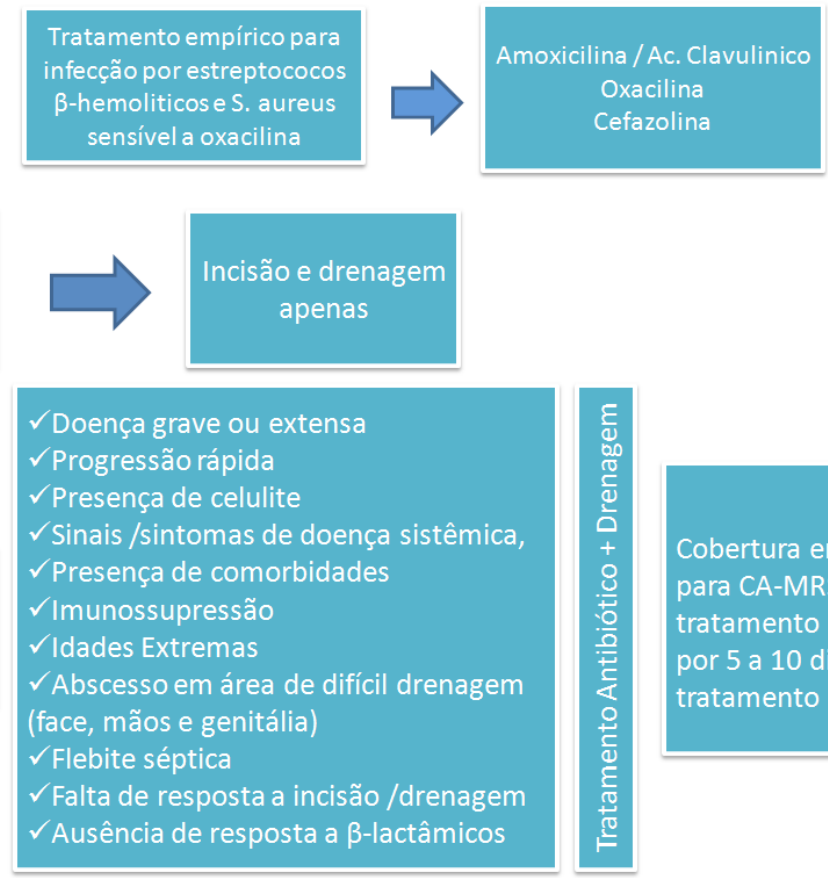

fato que foi confirmado usando o teste de Dickey-Fuller $\left(r^{2}=-0,007 ; p<0,05\right)$. Apesar do aumento no número do perfil-CA-MRSA observado no estudo, essa tendência não alcançou significância estatística $(\mathrm{p}=0,06)$ e a presença do perfil MSSA permaneceu estável no período do estudo $(\mathrm{p}=0,4)$. Adicionalmente foi realizado um estudo de caso e controle que avaliou os diferentes fenótipos, com o objetivo principal de identificar fatores associados com a mortalidade em infecções por $S$. aureus. No total foram avaliados 163 pacientes com infecções verdadeiras e observada internação prévia (três meses) em 55,8\% dos pacientes, sendo IRAS $71,7 \%$ dos episódios. O tipo de infecção mais frequente foi à ICS relacionada a uso de cateter venoso central (ICS-CVC) (33,7\%), seguido das infecções de pele e tecidos moles $(18,4 \%)$, pneumonia adquirida no hospital (PNH) (incluída a pneumonia associada a uso de ventilação mecânica - PAVM) (11\%) e as infecções de ferida operatória (IFO) $(18,4 \%)$. Após o episódio infeccioso, 111 pacientes receberam alta hospitalar $(68,1 \%)$, a mortalidade associada à infecção por $S$. aureus foi observada em 38 pacientes $(23,3 \%)$ e 14 pacientes $(8,6 \%)$ faleceram por outras causas. ${ }^{27}$

A comorbidade mais frequente foi a insuficiência renal crônica (IRC), especialmente nos pacientes submetidos à diálise $(44,2 \%)$. Também foram frequentes as doenças do tecido conectivo (22,9\%), diabetes mellitus (20,2\%), insuficiência cardíaca congestiva (ICC) (17,8\%), doença arterial periférica obstrutiva $(17,2 \%)$, tumor sólido maligno $(13,5 \%)$ e acidente cerebrovascular (13,5\%). Das 163 amostras de S. aureus, 73 foram do perfil MSSA, 65 do perfil-CA-MRSA e 25 do perfil-HA-MRSA. Considerando a análise das características clínicas e demográficas em relação aos diferentes perfis, foi observado aumento significativo no tempo de permanência hospitalar dos pacientes com infecções pelo perfil-HA-MRSA $(32,8 \pm$ 8,3 dias) e perfil-CA-MRSA ( $31 \pm 4,3$ dias) comparados com os que tiveram MSSA (19,3 $\pm 3,4$ dias $)(\mathrm{p}<0,05)$. Também houve mais infecções pelo perfil-CA-MRSA nas unidades cirúrgicas em relação aos outros perfis $(\mathrm{p}<$ $0,05)$. No grupo de pacientes com infecções pelo perfil-HA-MRSA a coinfecção foi mais frequente $(\mathrm{p}<0,05)$. Nas outras variáveis analisadas não houve diferenças estatisticamente significativas, 
incluindo a taxa de mortalidade associada $(\mathrm{p}=0,7) . \mathrm{Na}$ análise multivariada, foram demonstradas como fatores independentes da mortalidade dos pacientes com episódios infecciosos por S. aureus, condições próprias da idade avançada (idade maior de 70 anos, presença de pneumonia hospitalar, doença pulmonar obstrutiva crônica e leucemia $(\mathrm{p}<$ $0,05)$ e não houve diferença na mortalidade associada a um perfil particular, somente foi observada uma ligeira tendência ao aumento da mortalidade em infecções por MSSA na primeira semana $(\mathrm{p}=0,07)$ (Figura 3 ).

Em um subgrupo de 61 amostras MRSA do HUPE foi feita uma análise da susceptibilidade aos antimicrobianos utilizados em infecções graves por três metodologias (teste de discodifusão, análises das concentrações inibitórias mínimas (CIM) por E-test ${ }^{\curvearrowleft}$ e microdiluição em caldo). Todas as amostras foram sensíveis à vancomicina, teicoplanina, linezolida e daptomicina independente da metodologia usada. Houve uma boa correlação entre os valores da CIM obtidos no método padrão-ouro (microdiluição em caldo) e pelo E-test ${ }^{\oplus}$ para vancomicina em amostras que apresentaram valores de CIM maior de $2 \mu \mathrm{g} / \mathrm{ml}(\mathrm{p}=0,02)$.

\section{Estratégias de prevenção nas infecções por Staphylococcus aureus}

Existem várias publicações recentes que apresentam em forma detalhada estratégias para prevenção e tratamento de infecções por MRSA. ${ }^{28,29}$ Todos esses protocolos recomendam atividades de controle da disseminação do MRSA e incluem: 1) redução do uso de antibióticos, especialmente daqueles que induzem resistência em S. aureus, como as quinolonas; 2) educação dos trabalhadores da área de saúde; 3 ) regulamentação de protocolos de higienização das mãos; 4) sistemas de vigilância epidemiológica ativa e 5) medidas de precaução de contato para pacientes colonizados com MRSA ou com alto risco para infecção por MRSA. A vigilância

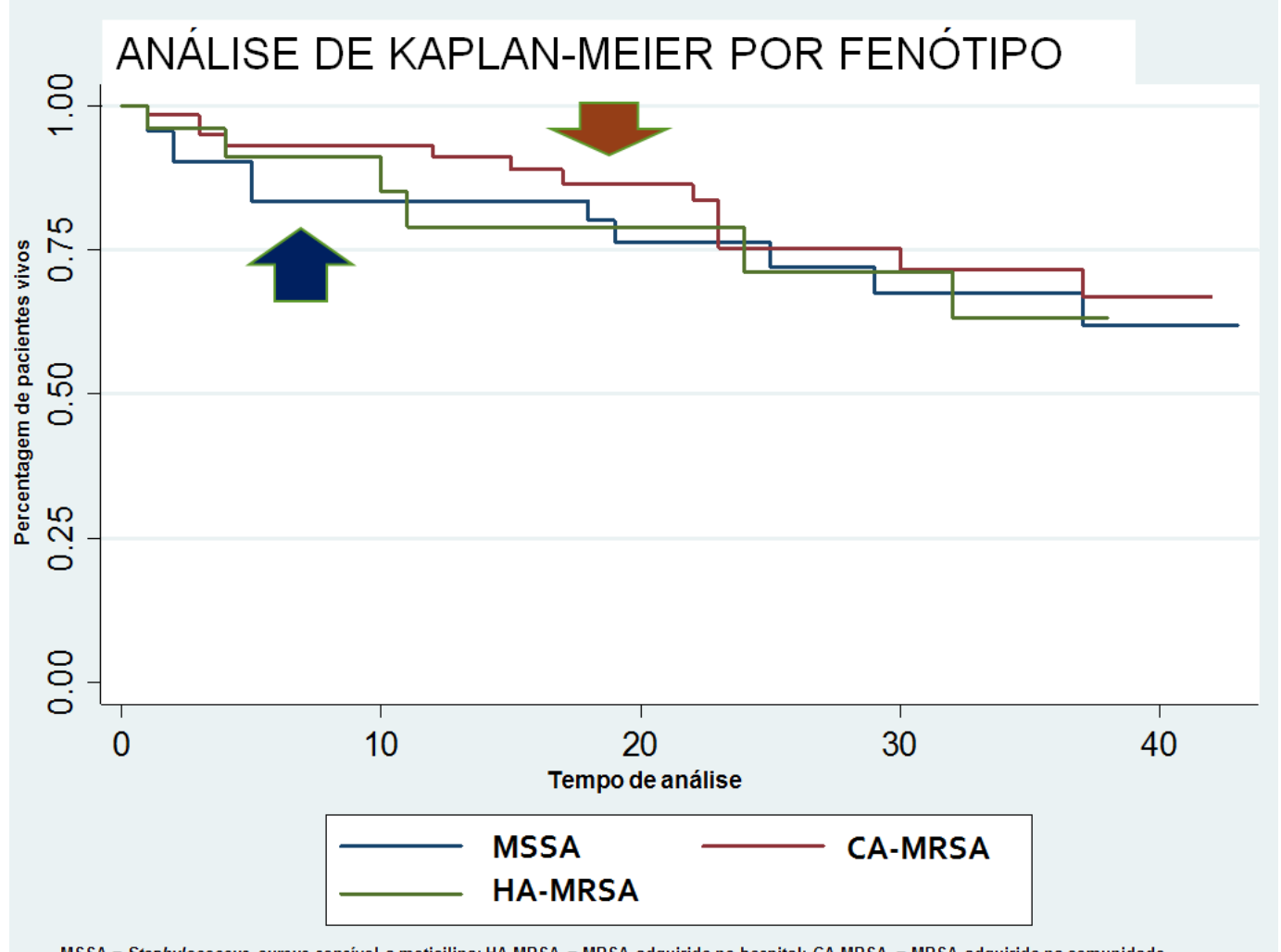

MSSA = Staphylococcus aureus sensivel a meticilina; HA-MRSA = MRSA adquirido no hospital; CA-MRSA = MRSA adquirido na comunidade.

Figura 3. Análises de sobrevida usando curvas de Kaplan-Meier da mortalidade relacionada à infecção por diferentes perfis fenotípicos de S. aureus 
ativa e os protocolos de coortes permanecem como medidas controversas, já que alguns estudos não têm demonstrado utilidade no controle da disseminação deste micro-organismo. As ações realizadas em alguns hospitais (isolamento de pacientes, higienização das mãos, racionalização no uso de antimicrobianos) têm reduzido a incidência de MRSA, como foi demonstrado recentemente. ${ }^{30}$

\section{Conclusões}

A dinâmica das infecções por MRSA em nosso hospital e em todos os hospitais brasileiros está mudando. Novas estratégias de controle de infecção devem ser procuradas e as antigas rotinas de prevenção devem ser reavaliadas. É imprescindível realizar estudos que caracterizem fatores de risco associados a infecções por CA-MRSA no conjunto hospitalar e no setor comunitário do Rio de Janeiro.

\section{Agradecimentos}

Agradecemos ao pessoal da comissão para o controle da infecção hospitalar do Hospital Universitário Pedro Ernesto e ao pessoal do departamento da Microbiologia da Faculdade de Ciências Médicas da Universidade do Estado do Rio de Janeiro.

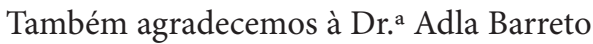
e ao Dr. Sérgio Cunha, que gentilmente fizeram uma revisão do artigo.

As pesquisas aqui apresentadas tiveram o apoio da Fundação de Amparo a Pesquisa do Estado do Rio de Janeiro - FAPERJ.

\section{Referências}

1. Newsom SW. Ogston's Coccus. J Hosp Infect. 2008;70:369-72. http://dx.doi.org/10.1016/j. jhin.2008.10.001

2. Kloos WE, Bannerman TL. Staphylococcus and Micrococcus. In: Murray PR, Baron EJ, Pfaller MA, et al. Manual of Clinical Microbiology. 6th ed. Washington, DC: ASM Press; 1995. p.282-98.

3. Patti JM, Allen BL, McGavin MJ, Höök M. MSCRAMM-mediated adherence of microorganisms to host tissues. Annu Rev
Microbiol. 1994;48:585-617.

4. Foster TJ. Immune evasion by staphylococci. Nat Rev Microbiol. 2005;3:948-58.

5. Fowler T, Wann ER, Joh D, Johansson S, Foster TJ, Höök M. Cellular invasion by Staphylococcus aureus involves a fibronectin bridge between the bacterial fibronectinbinding MSCRAMMs and host cell beta1 integrins. Eur J Cell Biol. 2000;79:672-9.

6. Labandeira-Rey M, Couzon F, Boisset S, Brown EL, Bes M, Benito Y, et al. Staphylococcus aureus Panton-Valentine leukocidin causes necrotizing pneumonia. Science. 2007 Feb 23;315(5815):1130-3.

7. Damasco PV, Chamon RC, Barbosa AT, Cunha S, Aquino JH, Cavalcante FS, et al. Involvement of methicillin-susceptible Staphylococcus aureus related to sequence type 25 and harboring pvl genes in a case of carotid cavernous fistula after communityassociated sepsis. J Clin Microbiol. 2012;50 (1):196. http://dx.doi.org/10.1128/JCM.00972-11

8. Georgopapadakou NH. Penicillin-binding proteins and bacterial resistance to betalactams. Antimicrob Agents Chemother 1993;37:2045-53.

9. Ito T, Okuma K, Ma XX, Yuzawa H, Hiramatsu K. Insights on antibiotic resistance of Staphylococcus aureus from its whole genome: genomic island SCC. Drug Resist Updat. 2003;6:41-52.

10. Shore AC, Deasy EC, Slickers P, Brennan G, O'Connell B, Monecke S, et al. Detection of staphylococcal cassette chromosome mec type XI carrying highly divergent mecA, mecI, mecR1, blaZ, and ccr genes in human clinical isolates of clonal complex 130 methicillinresistant Staphylococcus aureus. Antimicrob Agents Chemother. 2011 Aug;55(8):3765-73. http://dx.doi.org/10.1128/AAC.00187-11

11. Forcade NA, Parchman ML, Jorgensen JH, Du LC, Nyren NR, Treviño LB, et al. Prevalence, Severity, and Treatment of CommunityAcquired Methicillin-Resistant Staphylococcus aureus (CA-MRSA) Skin and Soft Tissue Infections in 10 Medical Clinics in Texas: A South Texas Ambulatory Research Network (STARNet) Study. J Am Board Fam Med. 2011 Sep-Oct;24(5):543-50. http://dx.doi. org/10.3122/jabfm.2011.05.110073

12. Lina G, Piémont $Y$, Godail-Gamot F, Bes M, Peter MO, Gauduchon V, et al. Involvement of Panton-Valentine leukocidin-producing Staphylococcus aureus in primary skin infections and pneumonia. Clin Infect Dis. 1999 Nov;29(5):1128-32.

13. Deurenberg RH, Stobberingh EE. The 
evolution of Staphylococcus aureus. Infection, Genetics and Evolution. 2008;8(6):747-63. http://dx.doi.org/10.1016/j.meegid.2008.07.007

14. David MZ, Daum RS. Community-associated methicillin-resistant Staphylococcus aureus: epidemiology and clinical consequences of an emerging epidemic.Clin Microbiol Rev. 2010 Jul;23(3):616-87. http://dx.doi.org/10.1128/ CMR.00081-09

15. Seybold U, Kourbatova EV, Johnson JG, Halvosa SJ, Wang YF, King MD, et al. Emergence of community-associated methicillin-resistant Staphylococcus aureus USA300 genotype as a major cause of health care-associated blood stream infections. Clin Infect Dis. 2006;42:647-56.

16. Chung HJ, Jeon HS, Sung H, Kim MN, Hong SJ. Epidemiological characteristics of methicillin-resistant Staphylococcus aureus isolates from children with eczematous atopic dermatitis lesions. J Clin Microbiol. 2008 Mar;46(3):991-5. http://dx.doi.org/10.1128/ JCM.00698-07

17. Moreira MR, Cardoso RL, Almeida AB, Gontijo Filho PP. Risk factors and evolution of Ventilator-associated pneumonia by Staphylococcus aureus sensitive or resistant to Oxacillin in patients at Intensive Care Unit of a Brazilian University Hospital. Braz J Infect Dis. 2008;12(6):499-503.

18. Tang YW, Stratton CW. Staphylococcus aureus: An old pathogen with new weapons. Clin Lab Med. 2010;30:179-208.

19. Yanagisawa C, Hanaki H, Natae T, Sunakawa K. Neutralization of staphylococcal exotoxins in vitro by human-origin intravenous immunoglobulin. J Infect Chemother. 2007;13:368-72.

20. Gould IM, Cauda R, Esposito S, Gudiol F, Mazzei T, Garau J. Management of serious meticillin-resistant Staphylococcus aureus infections: what are the limits? Int J Antimicrob Agents. 2011 Mar;37(3):202-9.

21. Cereda RF, Azevedo HD, Girardello R, Xavier DE, Gales AC, INVITA-A-CEFTO Brazilian Study Group. INVITA-A-CEFTO Brazilian Study Group. Antimicrobial activity of ceftobiprole against Gram-negative and Gram- positive pathogens: results from INVITA-A-CEFTO Brazilian study. Braz J Infect Dis. 2011 Aug;15(4):339-48.

22. Moore CL, Lu M, Cheema F, OsakiKiyan P, Perri MB, Donabedian S, et al. Prediction of Failure in Vancomycin-Treated Methicillin-Resistant Staphylococcus aureus Bloodstream Infection: a Clinically Useful Risk Stratification Tool. Antimicrob Agents Chemother. 2011 Oct;55(10):4581-8. http://
dx.doi.org/10.1128/AAC.00115-11

23. Naimi TS, LeDell KH, Como-Sabetti K, Borchardt SM, Boxrud DJ, Etienne J, et al. Comparison of community-and health careassociated methicillin-resistant Staphylococcus aureus infection. JAMA. 2003; 290:2976-84.

24. Popovich KJ, Weinstein RA, Hota B. Are Community-Associated Methicillin-Resistant Staphylococcus aureus (MRSA) Strains Replacing Traditional Nosocomial MRSA Strains Clin Infect Dis. 2008;46:787-94.

25. Eveillard M, de Lassence A, Lancien E, Barnaud G, Ricard JD, Joly-Guillou ML. Evaluation of a strategy of screening multiple anatomical sites for methicillinresistant Staphylococcus aureus at admission to a teaching hospital. Infect Control Hosp Epidemiol. 2006;27:181-4.

26. Trindade PA, Pacheco RL, Costa SF, Rossi F, Barone AA, Mamizuka EM, et al. Prevalence of SCCmec Type IV in Nosocomial Bloodstream Isolates of Methicillin-Resistant Staphylococcus aureus. J Clin Microbiol. July 2005;43(7):3435-7

27. Delgado JC, Marques EA, Werneck GL. Epidemiologia das infecções causadas por Staphylococcus aureus resistente a meticilina com perfil comunitário (CA-MRSA) em pacientes atendidos em um hospital terciário no Rio de Janeiro. Dissertação.Universidade do Estado do Rio de Janeiro, Faculdade de Ciências Médicas. Pós-graduação em Ciências Medicas; 2011.

28. Liu C, Bayer A, Cosgrove SE, Daum RS, Fridkin SK, Gorwitz RJ, et al. Clinical practice guidelines by the Infectious Society of America for the treatment of MethicillinResistant Staphylococcus aureus infections in adults and children. Clin Infect Dis. 11 Feb 1;52(3):e18-55. http://dx.doi.org/10.1093/cid/ ciq146.

29. Crowe M, Cunney R, Devitt E, et al. The control and prevention of MRSA in hospitals and in the community. Sari Infection Control Subcommittee. Ireland [acesso em 2012 Oct 25] Disponível em: http://www.hpsc.ie/A-Z/ Microbiology/AntimicrobialResistance/ InfectionControlandHAI/Guidelines/ File,1048,en.pdf

30. Tacconelli E. Methicillin-resistant Staphylococcus aureus: source control and surveillance organization. Clin Microbiol Infect. 2009;15(Suppl 7):31-8. http://dx.doi. org/10.1111/j.1469-0691.2009.03096.x 


\section{Anexos}

Quadro 1. Infecção de pele e partes moles (IPPM)

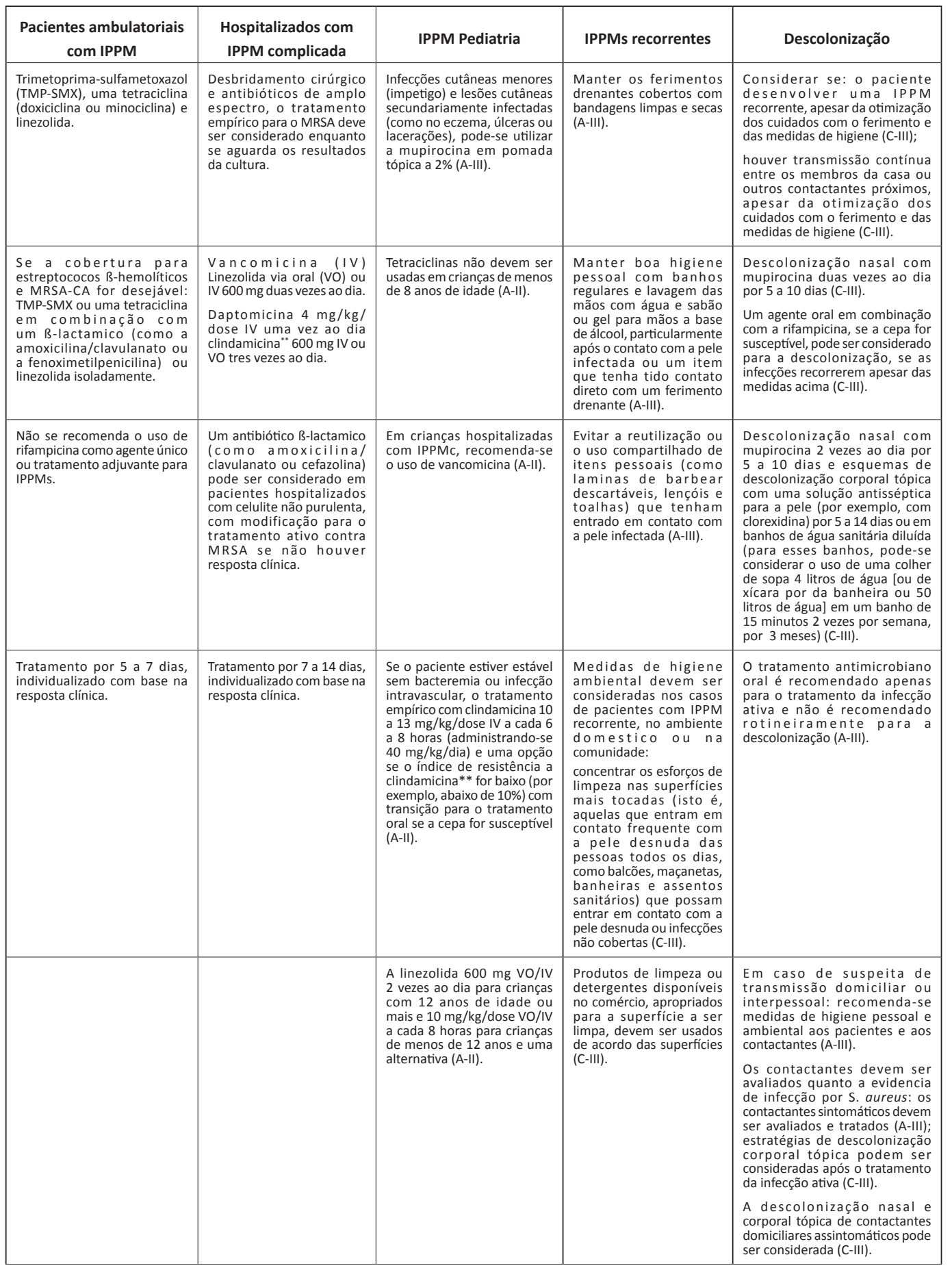

"'A frequência de resistência à clindamicina nas amostras de Staphylococcus aureus sensivel e resistente à meticilina no HUPE foi observada em aproximadamente $35 \%$ dos isolados, e esta pode ser superior devido ao fato de que não foi testada rotineiramente resistência do tipo MLSB. O papel das culturas no manejo de pacientes com IPPMs recorrentes e limitado: a coleta de culturas antes da descolonização não é recomendada rotineiramente, se ao menos uma das infecções prévias tiver sido documentada como devida ao MRSA (B-III). Culturas de vigilância após um esquema de descolonização não são recomendadas rotineiramente na ausência de uma infecção ativa (B-I). 


\section{Quadro 2. Endocardite e bacteremia}

\begin{tabular}{|c|c|c|c|}
\hline Bacteremia & $\begin{array}{l}\text { Endocardite infecciosa, valva } \\
\text { nativa }\end{array}$ & $\begin{array}{l}\text { Endocardite infecciosa, } \\
\text { prótese valvular }\end{array}$ & $\begin{array}{l}\text { Endocardite infecciosa } \\
\text { pediátrica }\end{array}$ \\
\hline $\begin{array}{l}\text { Em bacteremia não complicada } \\
\text { (definida pelos resultados positivos de } \\
\text { hemocultura eos seguintes requisitos: } \\
\text { exclusão de endocardite; sem } \\
\text { próteses implantadas; hemoculturas } \\
\text { de acompanhamento realizadas em } \\
\text { espécimes obtidas } 2 \text { a } 4 \text { dias após } \\
\text { o exame inicial sem crescimento de } \\
\text { MRSA; defervescência dentro de } 72 \\
\text { horas após o início do tratamento } \\
\text { efetivo; sem evidências de metástases } \\
\text { da infecção), recomenda-se o uso de } \\
\text { vancomicina (A-II) ou daptomicina } 6 \\
\text { mg/kg/dose IV } 1 \text { vez ao dia (A-I) por } \\
\text { no mínimo } 2 \text { semanas. }\end{array}$ & $\begin{array}{l}\text { Vancomicina IV (A-II) ou daptomicina } \\
6 \mathrm{mg} / \mathrm{kg} / \text { dose IV uma vez ao dia (A-I) } \\
\text { por } 6 \text { semanas. } \\
\text { Alguns especialistas recomendam } \\
\text { dosagens mais altas de daptomicina, } \\
\text { entre } 8 \text { e } 10 \mathrm{mg} / \mathrm{kg} / \text { dose IV } 1 \text { vez ao } \\
\text { dia (B-III). }\end{array}$ & $\begin{array}{l}\text { Vancomicina IV mais rifampicina } \\
300 \mathrm{mg} \text { VO/IV a cada } 8 \text { horas por no } \\
\text { mínimo } 6 \text { semanas, mais gentamicina } \\
1 \mathrm{mg} / \mathrm{kg} / \mathrm{dose} \text { IV a cada } 8 \text { horas por } 2 \\
\text { semanas (B-III). }\end{array}$ & $\begin{array}{l}\text { Vancomicina } 15 \mathrm{mg} / \mathrm{kg} / \mathrm{dose} \text { IV a } \\
\text { cada } 6 \text { horas para o tratamento } \\
\text { da bacteremia e da endocardite } \\
\text { infecciosa (A-II). }\end{array}$ \\
\hline \multirow[t]{5}{*}{$\begin{array}{l}\text { Para a bacteremia complicada } \\
\text { (definida pelos resultados positivos } \\
\text { de hemocultura que não preenchem } \\
\text { os critérios para bacteremia não } \\
\text { complicada), recomendam-se } 4 \text { a } 6 \\
\text { semanas de tratamento, dependendo } \\
\text { da extensão da infecção. Alguns } \\
\text { especialistas recomendam dosagens } \\
\text { mais altas de daptomicina, entre } 8 \text { e } \\
10 \mathrm{mg} / \mathrm{kg} / \text { dose IV } 1 \text { vez ao dia (B-III). }\end{array}$} & $\begin{array}{l}\text { A adição de gentamicina a } \\
\text { vancomicina não é recomendada } \\
\text { para a bacteremia ou endocardite } \\
\text { infecciosa com valva nativa (A-II). }\end{array}$ & $\begin{array}{l}\text { Recomenda-se avaliação precoce } \\
\text { de cirurgia para substituição da } \\
\text { valva (A-II). }\end{array}$ & $\begin{array}{l}\text { A duração do tratamento pode variar } \\
\text { de } 2 \text { a } 6 \text { semanas, dependendo } \\
\text { da fonte, da presença de infecção } \\
\text { intravascular e de focos metastáticos } \\
\text { de infecção. Os dados referentes } \\
\text { à segurança e eficácia de agentes } \\
\text { alternativos em crianças sãolimitados, } \\
\text { embora a daptomicina } 6 \text { a } 10 \mathrm{mg} / \mathrm{kg} / \\
\text { dose IV } 1 \text { vez ao dia possa ser uma } \\
\text { opção (C-III). }\end{array}$ \\
\hline & $\begin{array}{l}\text { A adição de rifampicina a vancomicina } \\
\text { não é recomendada para a bacteremia } \\
\text { ou endocardite infecciosa com valva } \\
\text { nativa (A-I). }\end{array}$ & & $\begin{array}{l}\text { Não se deve utilizar a clindamicina } \\
\text { ou a linezolida se houver suspeita } \\
\text { de endocardite infecciosa ou fonte } \\
\text { intravascular de infeção, mas esses } \\
\text { agentes podem ser considerados em } \\
\text { crianças cuja bacteremia desapareça } \\
\text { rapidamente e não esteja relacionada } \\
\text { a um foco intravascular (B-III). }\end{array}$ \\
\hline & $\begin{array}{l}\text { Deve-se realizar investigação clínica } \\
\text { para identificação da fonte e extensão } \\
\text { da infecção, com eliminação e/ou } \\
\text { desbridamento de outros locais de } \\
\text { infeç̧ão (A-II). }\end{array}$ & & $\begin{array}{l}\text { Os dados são insuficientes para se } \\
\text { apoiarno uso de rotina da combinação } \\
\text { terapêutica com rifampicina } \\
\text { ou gentamicina em crianças com } \\
\text { bacteremia ou endocardite infecciosa } \\
\text { (C-III); a decisão de se utilizar a } \\
\text { combinação deve ser avaliada caso } \\
\text { a caso. }\end{array}$ \\
\hline & $\begin{array}{l}\text { Recomenda-se a realização de } \\
\text { ecocardiografia para todos os } \\
\text { pacientes adultos com bacteremia. } \\
\text { A ecocardiografia transesofágica } \\
\text { (ETE) e preferível a ecocardiografia } \\
\text { transtorácica (ETT) (A-II). }\end{array}$ & & \\
\hline & $\begin{array}{l}\text { A avaliação para cirurgia de substituição } \\
\text { da valva é recomendada se houver } \\
\text { uma grande lesão vegetativa (mais } \\
\text { de } 10 \mathrm{~mm} \text { de diâmetro), ocorrência } \\
\text { de mais de um evento embólico nas } \\
\text { primeiras } 2 \text { semanas de tratamento, } \\
\text { insuficiên ncia valvular grave, } \\
\text { perfuração ou deiscência valvular, } \\
\text { insuficiência cardíaca descompensada, } \\
\text { abscesso perivalvular ou miocárdico, } \\
\text { aparecimento de bloqueio de } \\
\text { condução cardíaca, ou na presença de } \\
\text { febre ou bacteremia persistentes (A-II). }\end{array}$ & & \\
\hline
\end{tabular}

\section{Quadro 3. Pneumonia}

\begin{tabular}{|l|l|l|}
\hline $\begin{array}{c}\text { Hospitalizados com pneumonia } \\
\text { grave adquirida na comunidade* }\end{array}$ & $\begin{array}{c}\text { Pneumonia por MRSA associada aos serviços } \\
\text { de saúde (MRSA-SS) ou por MRSA-CA }\end{array}$ & Pneumonia em pediatria \\
\hline $\begin{array}{l}\text { Recomenda-se o tratamento empírico } \\
\text { para MRSA, enquanto se aguarda os } \\
\text { resultados da cultura de escarro e/ou } \\
\text { sangue (A-III). }\end{array}$ & $\begin{array}{l}\text { Vancomicina IV (A-II) ou linezolida } 600 \mathrm{mg} \text { VO/IV } 2 \text { vezes } \\
\text { ao dia (A-II) ou clindamicina } 600 \mathrm{mg} \text { VO/IV } 3 \text { vezes ao } \\
\text { dia (B-III), se a cepa for susceptível, por } 7 \text { a } 21 \text { dias, }, \\
\text { dependendo da extensão da infeç̧ão. }\end{array}$ & $\begin{array}{l}\text { Em crianças, recomenda-se o uso de vancomicina IV } \\
\text { (A-II). Se paciente estiver estável sem bacteremia ou } \\
\text { infecça intravascular, pode-se usar a clindamicina } 10 \text { a } \\
13 \mathrm{mg} / \mathrm{kg} / \text { dose IV a cada } 6 \text { a } 8 \text { horas (administrando-se } \\
40 \mathrm{mg} / \mathrm{kg} / \text { dia) se a cepa for susceptível, com transição } \\
\text { para o tratamento oral (A-II). }\end{array}$ \\
\hline & $\begin{array}{l}\text { Em pacientes com pneumonia por MRSA complicada por } \\
\text { empiema, deve-se usar o tratamento antimicrobiano } \\
\text { contra o MRSA associado a procedimentos de drenagem } \\
\text { (A-III). }\end{array}$ & $\begin{array}{l}\text { A linezolida } 600 \mathrm{mg} \text { Vo/IV } 2 \text { vezes ao dia para crianças } \\
\text { acima de } 12 \text { anos de idade e } 10 \mathrm{mg} / \mathrm{kg} / \mathrm{dose} \text { a cada } \\
8 \text { horas para crianças de ate } 12 \text { anos de idade e uma } \\
\text { alternativa (A-II). }\end{array}$ \\
\hline
\end{tabular}

*Definida por um dos seguintes critérios:

(1) necessidade de internação em unidade de terapia intensiva (UTI);

(2) infiltrados necrotizantes ou cavitários;

(3) empiema. 
Quadro 4. Infecções ósseas e articulares

\begin{tabular}{|c|c|c|c|}
\hline Osteomielite & Artrite séptica & $\begin{array}{l}\text { Infecções osteoarticulares } \\
\text { relacionadas a próteses }\end{array}$ & $\begin{array}{l}\text { Infecções ósseas e } \\
\text { articulares pediátricas }\end{array}$ \\
\hline $\begin{array}{l}\text { O desbridamento cirúrgico e a drenagem } \\
\text { dos abscessos de partes moles associados } \\
\text { constituem a base do tratamento e devem } \\
\text { ser realizados sempre que possível (A-II). }\end{array}$ & $\begin{array}{l}\text { A d r e } n \text { a g e m o u } \\
\text { desbridamento do espaço } \\
\text { articular deve ser realizada } \\
\text { sempre (A-II). } \\
\text { Na artrite séptica, siga as } \\
\text { opções de antibiótico para } \\
\text { a osteomielite. }\end{array}$ & $\begin{array}{l}\text { Nas infecções articulares precoces (menos de } 2 \\
\text { meses após a cirurgia) ou infecções em próteses } \\
\text { articulares com implante estável e curta } \\
\text { duração dos sintomas ( } 3 \text { semanas ou menos) } \\
\text { e desbridamento (com retenção da prótese), } \\
\text { iniciar tratamento parenteral (de acordo com } \\
\text { as recomendações para osteomielite) mais } \\
\text { rifampicina } 600 \mathrm{mg} \text { ao dia ou } 300 \text { a } 450 \mathrm{mg} \\
\text { VO } 2 \text { vezes ao dia por } 2 \text { semanas, seguido de } \\
\text { rifampicina mais } 1 \text { fluoroquinolona, TMP-SMX, } \\
1 \text { tetraciclina ou clindamicina se a cepa for } \\
\text { susceptivel por } 3 \text { a } 6 \text { meses para as próteses de } \\
\text { quadril e joelho, respectivamente (A-II). }\end{array}$ & $\begin{array}{l}\text { Em crianças com osteomielite e } \\
\text { artrite séptica aguda hematogenica } \\
\text { por MRSA, recomenda-se o uso de } \\
\text { vancomicina IV (A-II). }\end{array}$ \\
\hline $\begin{array}{l}\text { A via de administração ideal para } \\
\text { a antibioticoterapia ainda não foi } \\
\text { estabelecida. Pode-se usar o tratamento } \\
\text { parenteral ou oral, ou o tratamento inicial } \\
\text { parenteral seguido do tratamento oral, } \\
\text { dependendo das circunstancias individuais } \\
\text { do paciente (A-III). }\end{array}$ & $\begin{array}{l}\text { Sugere-se um ciclo de } 3 \text { a } \\
4 \text { semanas de tratamento } \\
\text { (A-III). }\end{array}$ & $\begin{array}{l}\text { O desbridamento imediato com remoção da } \\
\text { prótese sempre que possível e recomendado } \\
\text { para os implantes instáveis, as infecções tardias } \\
\text { ou os casos com longa duração (mais de } 3 \\
\text { semanas) dos sintomas (A-II). }\end{array}$ & $\begin{array}{l}\text { Se o paciente estiver estável } \\
\text { sem bacteremia ou infecção } \\
\text { intravascular, pode-se usar } \\
\text { clindamicina } 10 \text { a } 13 \mathrm{mg} / \mathrm{kg} / \mathrm{dose} \text { IV } \\
\text { a cada } 6 \text { a } 8 \text { horas (administrando- } \\
\text { se } 40 \mathrm{mg} / \mathrm{kg} / \mathrm{dia} \text { ) se a cepa for } \\
\text { susceptível, com transição para o } \\
\text { tratamento oral (A-II). }\end{array}$ \\
\hline $\begin{array}{l}\text { Os antibióticos disponíveis para a } \\
\text { administração parenteral incluem a } \\
\text { vancomicina IV (B-II) e a daptomicina } \\
6 \mathrm{mg} / \mathrm{kg} / \text { dose IV } 1 \text { vez ao dia (B-II). } \\
\text { Algumas opções de antibióticos com vias } \\
\text { de administração parenteral e oral: TMP- } \\
\text { SMX } 4 \mathrm{mg} / \mathrm{kg} / \text { dose de TMP } 2 \text { vezes ao dia } \\
\text { em combinação com rifampicina } 600 \mathrm{mg} 1 \\
\text { vez ao dia (B-II), linezolida } 600 \mathrm{mg} 2 \text { vezes } \\
\text { ao dia (B-II) e clindamicina } 600 \mathrm{mg} \text { a cada } \\
8 \text { horas se a cepa for susceptível (B-III). }\end{array}$ & & $\begin{array}{l}\text { Para as infecções precoces em implante da } \\
\text { coluna vertebral ( } 30 \text { dias ou menos após a } \\
\text { cirurgia) ou implantes em local com infecção } \\
\text { ativa, recomenda-se o tratamento parenteral } \\
\text { inicial mais rifampicina, seguido de tratamento } \\
\text { oral prolongado (B-II). }\end{array}$ & $\begin{array}{l}\text { A duração exata do tratamento } \\
\text { deve ser definida caso a caso, mas } \\
\text { tipicamente recomenda-se um ciclo } \\
\text { mínimo de } 3 \text { a } 4 \text { semanas para a } \\
\text { artrite séptica é de } 4 \text { a } 6 \text { semanas } \\
\text { para a osteomielite. }\end{array}$ \\
\hline $\begin{array}{l}\text { Alguns especialistas recomendam a } \\
\text { adição de rifampicina } 600 \mathrm{mg} \text { por dia } \\
\text { ou } 300 \text { a } 450 \mathrm{mg} \text { VO } 2 \text { vezes por dia ao } \\
\text { antibiótico escolhido acima (B-III). Para } \\
\text { pacientes com bacteremia concomitante, } \\
\text { a rifampicina deve ser adicionada após o } \\
\text { fim da bacteremia. }\end{array}$ & & $\begin{array}{l}\text { A duração ideal do tratamento parenteral e oral } \\
\text { não esta clara; este último deve continuar até } \\
\text { que ocorra a fusão espinhal (B-II). }\end{array}$ & $\begin{array}{l}\text { Alternativas a vancomicina e a } \\
\text { clindamicina: daptomicina } 6 \mathrm{mg} / \\
\mathrm{kg} / \mathrm{dia} \text { IV } 1 \text { vez ao dia (C-III) ou } \\
\text { linezolida } 600 \mathrm{mg} \text { VO/IV } 2 \text { vezes ao } \\
\text { dia para crianças de } 12 \text { anos ou mais } \\
\text { é } 10 \mathrm{mg} / \mathrm{kg} / \text { dose a cada } 8 \text { horas } \\
\text { para crianças de menos de } 12 \text { anos } \\
\text { de idade (C-III). }\end{array}$ \\
\hline $\begin{array}{l}\text { Alguns especialistas sugerem um período } \\
\text { adicional de } 1 \text { a } 3 \text { meses (e possivelmente } \\
\text { mais longo na infecção crônica, ou se } \\
\text { não for realizado desbridamento) } \\
\text { com tratamento combinado à base de } \\
\text { rifampicina com TMP-SMX, doxiciclina- } \\
\text { minociclina, clindamicina ou } 1 \\
\text { fluoroquinolona, escolhido com base na } \\
\text { susceptibilidade da cepa (C-III). }\end{array}$ & & $\begin{array}{l}\text { Pode-se considerar o uso prolongado de } \\
\text { antibióticos supressivos (por exemplo, } \\
\text { TMP-SMX, } 1 \text { tetraciclina, } 1 \text { fluoroquinolona } \\
\text { [que deve ser administrada juntamente } \\
\text { com rifampicina, devido à possibilidade de } \\
\text { resistência à fluoroquinolona, principalmente } \\
\text { se o desbridamento cirúrgico adequado } \\
\text { não for possível] ou clindamicina), com ou } \\
\text { sem rifampicina em casos selecionados, } \\
\text { principalmente se a remoção da prótese não } \\
\text { for possível (B-III). }\end{array}$ & \\
\hline $\begin{array}{l}\text { A ressonância magnética (RM) com } \\
\text { gadolínio é o exame de imagem de } \\
\text { escolha, principalmente para a detecção } \\
\text { da osteomielite inicial e associada à } \\
\text { doença em partes moles (A-II). } \\
\\
\text { A velocidade de hemossedimentação (VHS) } \\
\text { e/ou o nível de proteína c-reativa (PCR) } \\
\text { podem ser úteis para orientar a resposta } \\
\text { ao tratamento (B-III). }\end{array}$ & & & \\
\hline
\end{tabular}

\section{Quadro 5. Infecções do sistema nervoso central}

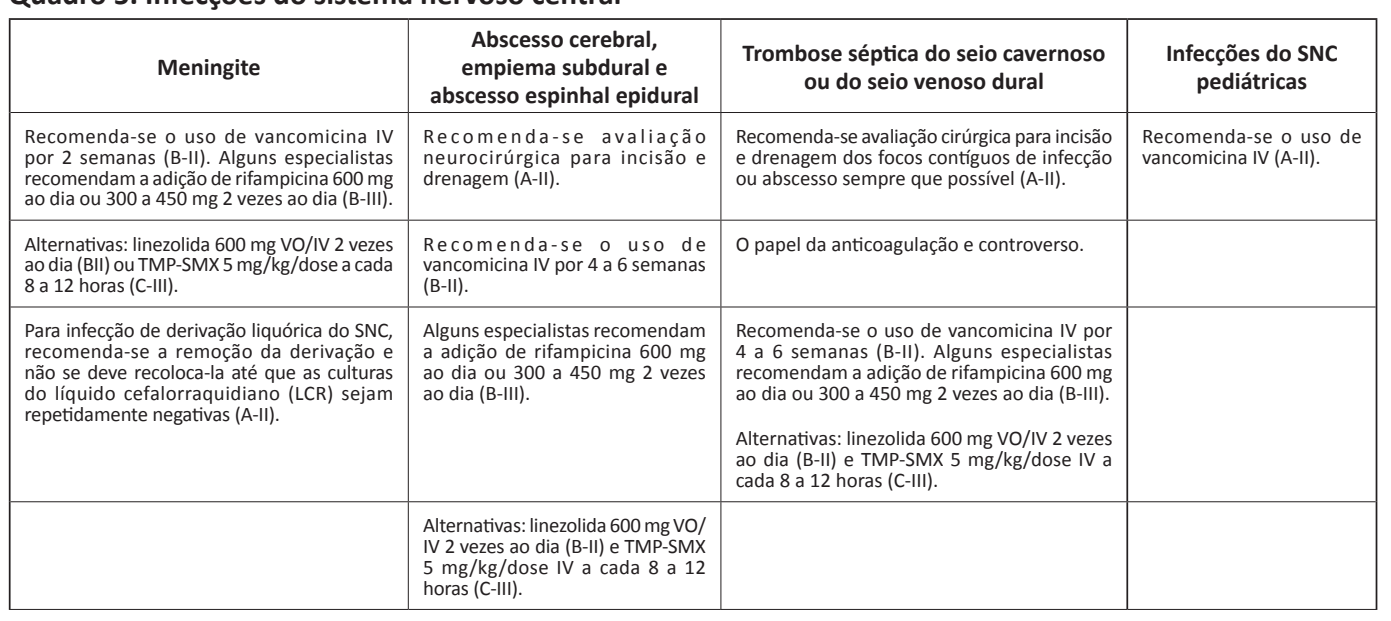


Quadro 6. Recomendações para a dosagem da vancomicina e o seu monitoramento

\begin{tabular}{|c|c|}
\hline $\begin{array}{l}\text { Recomenda-se o uso de vancomicina IV } 15 \text { a } 20 \mathrm{mg} / \mathrm{kg} / \text { dose (peso corporal } \\
\text { real) a cada } 8 \text { a } 12 \text { horas, não excedendo } 2 \mathrm{~g} \text { por dose, em pacientes com } \\
\text { função renal normal (B-III). }\end{array}$ & $\begin{array}{l}\text { As informações disponíveis são limitadas para orientar a dosagem de vancomicina } \\
\text { em crianças. Recomenda-se o uso de vancomicina na dosagem de } 15 \mathrm{mg} / \mathrm{kg} / \mathrm{dose} \\
\text { IV a cada } 6 \text { horas em crianças com doença grave ou invasiva (B-III). }\end{array}$ \\
\hline $\begin{array}{l}\text { Nos pacientes graves (como aqueles em sepse, meningite, pneumonia ou } \\
\text { endocardite infecciosa) com suspeita de infecção por MRSA, uma dose de ataque } \\
\text { de } 25 \text { a } 30 \mathrm{mg} / \mathrm{kg} \text { (peso corporal real) pode ser considerada. (Devido ao risco da } \\
\text { síndrome do homem vermelho e de possível anafilaxia associado a altas doses de } \\
\text { vancomicina, deve-se considerar o aumento do tempo de infusão para } 2 \text { horas e } \\
\text { o uso de um anti-histamínico antes da administração da dose de ataque) (C-III). }\end{array}$ & $\begin{array}{l}\text { A eficácia e a segurança das metas de concentraç̃ões de vale de } 15 \text { a } 20 \mu \mathrm{g} / \mathrm{ml} \\
\text { em crianças requerem estudos adicionais, mas devem ser consideradas naquelas } \\
\text { com infeç̧̃̃es graves, como bacteremia, endocardite infecciosa, osteomielite, } \\
\text { meningite, pneumonia e IPPM grave (como a fasceíte necrotizante) (B-III). }\end{array}$ \\
\hline $\begin{array}{l}\text { As concentrações de vale da vancomicina constituem o método mais acurado e } \\
\text { prático de orientar a sua dosagem (B-II). As concentrações séricas de vale devem } \\
\text { ser obtidas em condições de equilíbrio, antes da quarta ou quinta dose. Não se } \\
\text { recomenda o monitoramento das concentrações de pico da vancomicina (B-II). }\end{array}$ & \\
\hline $\begin{array}{l}\text { Para infecções graves, como bacteremia, endocardite infecciosa, osteomielite, } \\
\text { meningite, pneumonia e IPPM grave (como a fasceíte necrotizante) devidas } \\
\text { ao MRSA, recomendam-se concentrações de vale da vancomicina de } 15 \text { a } \\
20 \mu \mathrm{g} / \mathrm{ml} \text { (B-II). }\end{array}$ & \\
\hline $\begin{array}{l}\text { O monitoramento das concentrações de vale da vancomicina é recomendado } \\
\text { para as infecções graves e os pacientes com obesidade mórbida, com disfunção } \\
\text { renal (inclusive aqueles que estão em diálise) ou com volumes de distribuição } \\
\text { flutuante (A-II). }\end{array}$ & \\
\hline Não se recomenda esquemas de infusão contínua de vancomicina (A-II). & \\
\hline
\end{tabular}

\section{Quadro 7. Infecções por MRSA em neonatos}

\begin{tabular}{|c|c|c|}
\hline $\begin{array}{l}\text { Em casos leves com doença localizada, o tratamento } \\
\text { tópico com mupirocina pode ser adequado em } \\
\text { neonatos de termo e recém-nascidos novos (A-III). }\end{array}$ & $\begin{array}{l}\text { Prematuros ou recém-nascidos com peso muito } \\
\text { baixo ao nascer, ou na doença mais extensa, } \\
\text { envolvendo múltiplos focos em recém-nascidos } \\
\text { a termo, recomenda-se o uso de vancomicina ou } \\
\text { clindamicina IV, ao menos inicialmente, até que a } \\
\text { bacteremia seja excluída (A-II). }\end{array}$ & $\begin{array}{l}\text { Vancomicina IV. } \\
\text { Clindamicina e linezolida são alternativas para as } \\
\text { infecções não intravasculares (B-II). }\end{array}$ \\
\hline
\end{tabular}

\section{Quadro 8. Dificuldades na terapêutica das infecções}

\begin{tabular}{|l|l|}
\hline \multicolumn{1}{|c|}{ MIC aumentado para vancomicina } & Bacteremia persistente e falhas terapêuticas da vancomicina \\
\hline $\begin{array}{l}\text { Para isolados com uma concentração inibitória mínima (CIM) de vancomicina } \\
\text { de } 2 \mu \mathrm{\mu g} / \mathrm{ml} \text { ou menos (ou seja, susceptíveis, de acordo com os niveis de corte } \\
\text { definidos pelo Clinical and Laboratory Standards Institute [CLSI]), a resposta } \\
\text { clinica do paciente deve determinar o uso continuado da vancomicina, } \\
\text { independentemente da CIM (A-III). }\end{array}$ & $\begin{array}{l}\text { Recomenda-se buscar e remover outros focos de infecção, drenagem ou } \\
\text { desbridamento cirúrgico (A-III). }\end{array}$ \\
\hline $\begin{array}{l}\text { Se o paciente tiver apresentado resposta clínica e microbiológica a vancomicina, } \\
\text { o tratamento pode continuar com acompanhamento cuidadoso. }\end{array}$ & $\begin{array}{l}\text { Deve-se considerar o uso de daptomicina em alta dose (10 mg/kg/dia), se } \\
\text { o isolado for susceptível, em combinação com outro agente (por exemplo, } \\
\text { gentamicina } 1 \mathrm{mg} / \mathrm{kg} \text { IV a cada } 8 \text { horas, rifampicina } 600 \mathrm{mg} \text { VO/IV ao dia ou } 300 \\
\text { a 450 mg VO/IV } 2 \text { vezes ao dia, linezolida } 600 \mathrm{mg} \text { VO/IV } 2 \text { vezes ao dia, TMP-SMX } \\
5 \mathrm{mg} / \mathrm{kg} \text { IV } 2 \text { vezes ao dia ou um antibiótico B-lactamico) (B-III). }\end{array}$ \\
\hline $\begin{array}{l}\text { Se o paciente não tiver apresentado resposta clínica ou microbiológica } \\
\text { a vancomicina, apesar do desbridamento adequado e da remoção de } \\
\text { outros focos de infeç̧ão, recomenda-se uma alternativa a vancomicina, } \\
\text { independentemente da CIM. }\end{array}$ & $\begin{array}{l}\text { Se houver susceptibilidade reduzida à vancomicina e a daptomicina, a opção é: } \\
\text { linezolida } 600 \mathrm{mg} \text { VO/IV } 2 \text { vezes (C-III). }\end{array}$ \\
\hline $\begin{array}{l}\text { Para isolados com CIM da vancomicina acima de } 2 \mu \mathrm{gg} / \mathrm{ml} \text { (ou seja, S. aureus } \\
\text { com resistência intermediária à vancomicina [VISA] ou S. aureus resistente à } \\
\text { vancomicina [VRSA]), deve-se utilizar uma alternativa à vancomicina (A-III). }\end{array}$ & $\begin{array}{l}\text { Essas opçães podem ser usadas como agente único ou em combinação com } \\
\text { outros antibióticos. }\end{array}$ \\
\hline
\end{tabular}

Fonte: Adaptado de Clinical practice guidelines by the Infectious Society of America for the treatment of Methicillin-Resistant Staphylococcus aureus infections in adults and children, $2011 .^{28}$ 